\title{
Incorporating turnover in estimates of protein retention efficiency for different body tissues
}

\author{
C. Z. Roux* \\ Department of Genetics, University of Pretoria, Pretoria 0002, Republic of South Africa \\ (Received 18 February 2005 - Revised 16 August 2005 - Accepted 18 August 2005)
}

\begin{abstract}
Formulated in terms of protein synthesis (PS) and protein retention (PR), a definition of turnover-related protein retention efficiency $\left(\mathrm{k}_{\mathrm{P}}\right)$ allows the expression $\mathrm{k}_{\mathrm{P}}=[1+(\mathrm{PS} / \mathrm{PR}) / 6]^{-1}, 6$ representing the ratio of the energy equivalent of protein to the cost of synthesis. By combining plausible hormonal and cellular control mechanisms of protein $(\mathrm{P})$ growth, it is possible to derive $(\mathrm{PS} / \mathrm{PR})=\left[\mathrm{Q}\left\{(\mathrm{P} / \alpha)^{-(4 / 9) \mathrm{Y}}-1\right\}\right]^{-1}+1$, allowing the calculation of $\mathrm{k}_{\mathrm{P}}$ by substitution. The symbol $\alpha$ represents the limit value of protein growth, while the term $4 / 9$ derives from the power in the relationship between the concentration of growth factor-related activator in the nucleus and cell volume (cv). Y is the power in the relationship between cv and total tissue protein, and Q represents the proportion of growth factor-activated nuclei in a tissue. The proportion Q can be estimated from simple functions of intake rates or blood growth factor concentrations. Estimates of $\mathrm{Y}$ are derived from histological considerations or calculated from experimental observations; $\mathrm{Y}=1$ for multinucleated skeletal muscle fibres and $\mathrm{Y}=1 / 3,1 / 2,1 / 6$ on average for mononucleated cell tissues, skin or bone and viscera, respectively. To apply $k_{\mathrm{P}}$ to the whole body, an average value of $\mathrm{Y}=1 / 2$ can be taken. Experimental observations on tissue protein synthesis and breakdown rates yield direct estimates of $\mathrm{k}_{\mathrm{P}}$ in satisfactory agreement with comparable theoretical predictions.
\end{abstract}

Protein turnover: Protein retention efficiency: Body tissues

Bergen and Merkel (1991) suggested that the discrepancy between regression estimates of protein retention (PR) efficiency and theoretical estimates of synthesis efficiency indicated a major contribution ascribable to protein turnover in the generally accepted estimates. Quantification by Roux $(2005 a, b)$ has shown that this is indeed the situation for whole-body PR efficiency in pigs, cattle and sheep.

Theoretical values for the parameters in Roux (2005a) were derived using the assumption that heart values are representative of average values for the whole body. It was shown that the difference between protein synthesis and breakdown related to body protein according to the relationship between nuclear and tissue sizes during growth. It follows that ideas used in whole-body and heart scaling by Roux (2005a) can be extended to accommodate different aggregates of body tissues. In addition, two improved derivations are given in this paper. First, previously neglected ribosomal scaling (Roux, $2005 a$ ) is accommodated. Second, an exact estimate of $\mathrm{k}_{\mathrm{P}}$ is derived and compared with the previous approximation (Roux, 2005a), necessary for application in conjunction with established equations for growth description in the literature.

From a nutritional standpoint, differences in PR efficiency between tissues are important in two ways. The first is for predicting nutrient requirements for growth in different tissues from turnover-related efficiencies; the second is for estimating the contributions to maintenance from protein turnover in different tissues. The importance of tissue differences in efficiency and maintenance has been generally recognized, and quantification has been achieved by, among others, DiMarco et al. (1989) and van Milgen et al. (1998). The main advantage of this compared with previous approaches is that the theoretical predictions of PR efficiency derived are based on cellular and hormonal mechanisms of control over synthesis. Turnoverrelated efficiencies can be calculated from equation 2 or from equation 9, derived in the next section. The advantage of this can be seen in Table 1 (later in the paper). Note that the substantial differences in efficiency confirm the need for specialized estimates according to degree of maturity and tissue type. The values for skin or bone in Table 1 are also applicable to the whole-body protein efficiencies. Although Roux (2005a) should be consulted for a more rigorous argument, it can be noted here that the average of 0.52 is in quite reasonable agreement with the average of 0.55 from the Agricultural Research Council (1981) that can be calculated for whole-body values covering the same range of body masses as in Table 1 .

\section{Theory and methods}

Turnover-related protein retention efficiency

To allow the incorporation of turnover into the definition of PR efficiency $\left(\mathrm{k}_{\mathrm{P}}\right)$, it is convenient to follow Bergen \& Merkel (1991):

$$
\mathrm{k}_{\mathrm{P}}=22 \cdot 6 \mathrm{PR} /(22 \cdot 6 \mathrm{PR}+3 \cdot 766 \mathrm{PS}),
$$

Abbreviations: cv, cell volume; FPR, fractional protein retention; FPS, fractional protein synthesis; IGF, insulin-like growth factor; nv, nuclear volume; P/ $\alpha$, protein maturity; PB, protein breakdown; PR, protein retention; PS, protein synthesis; tm, tissue mass.

* Corresponding author: Professor C. Z. Roux, email ina.goosen@up.ac.za 
Table 1. A comparison of turnover protein retention efficiencies (equation 1 in the text) in pigs for different tissues at various degrees of protein maturity $(\mathrm{P} / \alpha)$, calculated according to equation 2 or 9 from the theoretically derived values of $\mathrm{j}(\mathrm{a}-\mathrm{b}$ with an intake ad libitum) (equation 26)

\begin{tabular}{|c|c|c|c|c|c|}
\hline Body mass $\mathrm{W}(\mathrm{kg})$ & Protein maturity $\mathrm{P} / \alpha$ & Skeletal muscle $\mathrm{j}=4 / 9$ & Skin or bone $\mathrm{j}=2 / 9$ & Mononucleate tissue $\mathrm{j}=4 / 27$ & Viscera $\mathrm{j}=2 / 27$ \\
\hline 20 & 0.1 & 0.79 & 0.71 & 0.63 & 0.48 \\
\hline 60 & $0 \cdot 3$ & 0.71 & 0.58 & 0.49 & 0.34 \\
\hline 140 & 0.7 & 0.47 & 0.31 & 0.24 & 0.14 \\
\hline Average & & 0.65 & 0.52 & 0.43 & 0.30 \\
\hline
\end{tabular}

where PR $(\mathrm{kg} / \mathrm{d})$ represents the rate of protein retention in a tissue and PS $(\mathrm{kg} / \mathrm{d})$ the rate of protein synthesis. The coefficient $22.6(\mathrm{MJ} / \mathrm{kg})$ represents the energy equivalent of protein and 3.766 the cost of synthesis based on the assumption that 5 moles ATP will arrange 1 mole peptide bonds. On dividing the ratio in equation 1 above and below by $22 \cdot 6, \mathrm{k}_{\mathrm{P}}$ becomes:

$$
\mathrm{k}_{\mathrm{P}}=[1+(\mathrm{PS} / \mathrm{PR}) / 6]^{-1} \text {. }
$$

If there is no turnover, or breakdown and resynthesis of existing protein, $\mathrm{PR}=\mathrm{PS}$, and $\mathrm{k}_{\mathrm{P}}=0 \cdot 86$, given as a theoretical value in Blaxter (1989). The rate of PR is equal to the difference between the rate of PS and the rate of protein breakdown $(\mathrm{PB})$ :

$$
\mathrm{PR}=\mathrm{PS}-\mathrm{PB} .
$$

It follows from both experimental and theoretical reasons, developed and quoted by Roux (2005a), that the rates of PB and synthesis can often be satisfactorily approximated by power equations:

$$
\mathrm{PB}=\mathrm{c}_{1} \mathrm{P}^{\mathrm{a}}=\mathrm{c}_{3}(\mathrm{P} / \alpha)^{\mathrm{a}}
$$

and

$$
\mathrm{PS}=\mathrm{c}_{2} \mathrm{P}^{\mathrm{b}}=\mathrm{c}_{4}(\mathrm{P} / \alpha)^{\mathrm{b}},
$$

$\mathrm{P}$ being the amount of protein in a tissue and $\alpha$ the amount of protein at maturity. As protein growth stops at maturity, equations 4 and 5 must be equal for $\mathrm{P}=\alpha$. Hence:

$$
\mathrm{c}_{3}=\mathrm{c}_{4}=\mathrm{c} \text {. }
$$

It therefore follows from equations 3-5 that:

$$
\mathrm{PR}=\mathrm{c}\left[(\mathrm{P} / \alpha)^{\mathrm{b}}-(\mathrm{P} / \alpha)^{\mathrm{a}}\right],
$$

and from equations 5-7 that:

$$
\begin{aligned}
\mathrm{PS} / \mathrm{PR} & =(\mathrm{P} / \alpha)^{\mathrm{b}} /\left[(\mathrm{P} / \alpha)^{\mathrm{b}}-(\mathrm{P} / \alpha)^{\mathrm{a}}\right] \\
& =\left[1-(\mathrm{P} / \alpha)^{\mathrm{a}-\mathrm{b}}\right]^{-1} .
\end{aligned}
$$

By substituting equation 8 in equation 2:

$$
\mathrm{k}_{\mathrm{P}}=\left\{1+\left[1-(\mathrm{P} / \alpha)^{\mathrm{a}-\mathrm{b}}\right]^{-1} / 6\right\}^{-1}
$$

is obtained.

Equation 9 is a crucial result, showing that, with the incorporation of turnover, $\mathrm{k}_{\mathrm{P}}$ is completely determined by just two parameters: the difference in breakdown and synthesis powers, and the limit value of tissue protein, $\alpha$. The effect of $\alpha$ is mediated via the variable $\mathrm{P} / \alpha$, which can be described as the degree of protein maturity. Consequently, for comparisons at equal stages of development, expressed in $\mathrm{P} / \alpha$, equation 9 indicates that all possible influences on turnover PR efficiency are mediated solely via the parameter $(\mathrm{a}-\mathrm{b})$. Hence, an evaluation of $(\mathrm{a}-\mathrm{b})$ is, for equal $\mathrm{P} / \alpha$, equivalent to an evaluation of turnover PR efficiency.

\section{Estimation of parameters determining protein retention efficiency}

The parameter $\alpha$ can be estimated from equations 4 and 5 by:

$$
\alpha=\left(c_{2} / c_{1}\right)^{1 /(a-b)},
$$

from Roux (2005a) or von Bertalanffy (1960). In addition to the direct estimation of $(\mathrm{a}-\mathrm{b})$ from equations 4 and 5 , it follows from equation 6 that:

$$
\mathrm{PB} / \mathrm{PS}=(\mathrm{P} / \alpha)^{\mathrm{a}-\mathrm{b}},
$$

so that $(a-b)$ can be estimated by:

$$
(\mathrm{a}-\mathrm{b})=\ln (\mathrm{PB} / \mathrm{PS}) / \ln (\mathrm{P} / \alpha) .
$$

\section{Whole body and its components}

Let $\mathrm{PB}_{\mathrm{i}}$ and $\mathrm{PS}_{\mathrm{i}}$ be the breakdown and synthesis rates for the ith body tissue or organ, for example, the viscera or the liver. In addition, total body $\mathrm{PB}$ and $\mathrm{PS}$ are the sum of all $\mathrm{PB}_{\mathrm{i}}$ and $\mathrm{PS}_{\mathrm{i}}$ for the tissues or organs, such that $\mathrm{PB}=\Sigma \mathrm{PB}_{\mathrm{i}}$. Expressing the proportion (fraction, $\mathrm{f}_{\mathrm{i}}$ ) $\mathrm{PS}_{\mathrm{i}}$ of $\mathrm{PS}$ by $\mathrm{f}_{\mathrm{i}}=\mathrm{PS}_{\mathrm{i}} / \Sigma \mathrm{PS}_{\mathrm{i}}$ gives:

$$
\mathrm{PB} / \mathrm{PS}=\Sigma \mathrm{f}_{\mathrm{i}}\left(\mathrm{PB}_{\mathrm{i}} / \mathrm{PS}_{\mathrm{i}}\right) \text {. }
$$

Analogous to equation $11, \mathrm{~PB}_{\mathrm{i}} / \mathrm{PS}_{\mathrm{i}}=(\mathrm{P} / \alpha)^{\mathrm{ai}-\mathrm{bi}}$, assuming for simplicity that all $\mathrm{P}_{\mathrm{i}} / \alpha_{\mathrm{i}}$ ratios are approximately equal. It then follows from equations 11 and 13 that:

$$
(\mathrm{P} / \alpha)^{\mathrm{a}-\mathrm{b}}=\mathrm{PB} / \mathrm{PS}=\Sigma \mathrm{f}_{\mathrm{i}}(\mathrm{P} / \alpha)^{\mathrm{ai}-\mathrm{bi}} .
$$

The arithmetic mean of $(\mathrm{P} / \alpha)^{\mathrm{a} i-\mathrm{bi}}$ on the right-hand side of equation 14 can be approximated by a geometric mean so that $(\mathrm{P} / \alpha)^{\mathrm{a}-\mathrm{b}}=(\mathrm{P} / \alpha)^{2 \mathrm{f}(\mathrm{ai}-\mathrm{bi})}$. Hence, on equating powers:

$$
(\mathrm{a}-\mathrm{b})=\Sigma \mathrm{f}_{\mathrm{i}}\left(\mathrm{a}_{\mathrm{i}}-\mathrm{b}_{\mathrm{i}}\right),
$$

often to satisfactory approximation, as can be numerically verified for typical values of the quantities on the right-hand side of equation 15 .

Equation 15 means that the total body $(\mathrm{a}-\mathrm{b})$ is approximately equal to a weighted average of body component $\left(a_{i}-b_{i}\right)$ values, with the weights in proportion to a component's relative contribution to the total body synthesis rate, $\mathrm{f}_{\mathrm{i}}=\mathrm{PS}_{\mathrm{i}} / \Sigma \mathrm{PS} \mathrm{S}_{\mathrm{i}}$.

\section{Hormonal control in terms of quiescent and active nuclei}

The aim of this section is to develop a theoretical basis for predicting PR efficiency in different tissues or organs, 
together with appraising the influence of intake rate on efficiency. The discussion on equation 9 indicates that this can be accomplished by an analysis of the hormonal mediation of the relationship between $(\mathrm{a}-\mathrm{b})$ and cell and nucleus geometries for different tissues, which is easy to achieve. A quiescent cell can be described as not being involved in growth or division, although other functions generally may continue as usual. By extension, a quiescent nucleus is one that does not contribute to an increase in cell mass or cell division, i.e. a nucleus for which the associated synthesis (PS) and breakdown (PB) rates of protein are equal (i.e. $\mathrm{PS}=\mathrm{PB}$ ). In contrast, an active nucleus can be defined as one that contributes to an increase in cell mass or number (i.e. $\mathrm{PS}>\mathrm{PB}$ ).

For a quiescent nucleus, we can assume that $\mathrm{PB}=\mathrm{PS} \propto$ $(\mathrm{P} / \alpha)^{\mathrm{X}}$, with the power $\mathrm{X}$ possibly unequal to zero to allow for changes in ribosomal activity (Simon, 1989) with age, diet or other factors. It can also be assumed that the number of nuclei $(\mathrm{nn})$ in a tissue with protein scales with protein content $(\mathrm{P})$ as $\mathrm{nn} \propto(\mathrm{P} / \alpha)^{\mathrm{Z}}$. With all nuclei in a tissue in the quiescent state, $\mathrm{PB}$ and PS will scale as:

$$
\mathrm{PB}=\mathrm{PS}=\mathrm{c}(\mathrm{P} / \alpha)^{\mathrm{X}+\mathrm{Z}} .
$$

In general, an active nucleus will be associated with a cell with a growth factor, such as insulin-like growth factor-1 (IGF1), bound to receptors on the cell surface. Such a binding of a growth factor to a receptor sets a cascading signalling pathway in motion owing to the phosphorylation of tyrosine kinase (Czech, 1989). The last step is that an activated cytoplasmic protein diffuses into the nucleus to form an activator that binds to an enhancer on the DNA in order to influence PS by stimulating gene transcription.

Multiple enhancers, silencers and promoters control the activities of a single transcription unit in metazoan gene regulation (Levine \& Tjian, 2003). Hence, it follows from the law of mass action that it is natural to suppose the specific rate of gene transcription per nucleus to be proportional to the product of nuclear activator and DNA concentrations. As cv cancels from both sides of such a presentation, and the amount of DNA per nucleus remains constant, it follows that the absolute rate of gene transcription per nucleus is proportional to activator concentration alone.

Assume that, for activated cytoplasmic protein, the signalling cascade between cell surface and nucleus contains such a number of steps that the activated protein concentration in the cytoplasm does not vary with cell size, and that the difference in concentration between the cytoplasm and nucleus is large enough that differences in nuclear concentration have a negligible effect on the concentration gradient. In terms of Fick's law, this means that the diffusion rate will vary only with nuclear dimensions. Activated protein concentration must be equal to the product of its diffusion rate and lifetime. Hence, if the activated protein lifetime remains constant during growth, the concentration of activated protein or activator in the nucleus will also vary only with the nuclear dimensions.

If we denote nuclear volume by nv, the nuclear linear dimension will be $\propto(\mathrm{nv})^{1 / 3}$, and also nuclear surface $\propto$ $(\mathrm{nv})^{2 / 3}$. Hence, from Fick's law, activator concentration, [activator $] \propto$ (nuclear surface)/[(nuclear linear dimension) (nv)]. Hence [activator] $\propto(\mathrm{nv})^{-2 / 3}$. From Teissier (1941), it generally holds for mammalian cells that $\mathrm{nv} \propto(\mathrm{cv})^{2 / 3}$. It follows that:

$$
\text { [activator] } \propto(\mathrm{nv})^{-2 / 3} \propto(\mathrm{cv})^{-4 / 9} .
$$

We assume that the rate of PS depends essentially on the rate of gene transcription (Latchman, 2005). Then, for synthesis rate per nucleus, it holds that PS $\propto$ [activator], when nuclei are activated from growth factors bound to receptors on the cell surface. With a summation of over all nuclei in a tissue, it follows, by the same argument that lead to equation 16, that $\mathrm{PS} \propto(\mathrm{P} / \alpha)^{\mathrm{X}+\mathrm{Z}}$ [activator]. Then, from equation 17:

$$
\mathrm{PS} \propto(\mathrm{P} / \alpha)^{\mathrm{X}+\mathrm{Z}}(\mathrm{cv})^{-4 / 9},
$$

provided that all nuclei in a tissue are in the active state. If it is assumed that $\mathrm{cv}$ is related to the $\mathrm{P} / \alpha$ of a tissue, such that $(\mathrm{cv}) \propto(\mathrm{P} / \alpha)^{\mathrm{Y}}$, equation 18 becomes:

$$
\mathrm{PS}=\mathrm{c}(\mathrm{P} / \alpha)^{\mathrm{X}+\mathrm{Z}-(4 / 9) \mathrm{Y}}
$$

with the constant in both equations 19 and 16 deriving from equation 6 .

The proportion of active nuclei in a tissue can be denoted by Q. Then, from the combination of active (equation 19) and quiescent nuclei (equation 16), a tissue will have a total synthesis rate of:

$$
\mathrm{PS}=\mathrm{c}\left[(1-\mathrm{Q})(\mathrm{P} / \alpha)^{\mathrm{X}+\mathrm{Z}}+\mathrm{Q}(\mathrm{P} / \alpha)^{\mathrm{X}+\mathrm{Z}-(4 / 9) \mathrm{Y}}\right] .
$$

For typical values of the quantities involved in total body synthesis rates, the arithmetic mean on the right hand side of equation 20 can be replaced by a geometric mean for values of $\mathrm{P} / \alpha>0.05$ (Roux, 2005a). Hence, in analogy to the whole-body situation:

$$
\begin{aligned}
\mathrm{PS} & =\mathrm{c}(\mathrm{P} / \alpha)^{(1-\mathrm{Q})(\mathrm{X}+\mathrm{Z})+\mathrm{Q}(\mathrm{X}+\mathrm{Z}-(4 / 9) \mathrm{Y})} \\
& =\mathrm{c}(\mathrm{P} / \alpha)^{\mathrm{X}+\mathrm{Z}-(4 / 9) \mathrm{YQ} .}
\end{aligned}
$$

A comparison of equations 21 and 16 with equations 5 and 4 indicates $\mathrm{a}=\mathrm{X}+\mathrm{Z}$, and $\mathrm{b}=\mathrm{X}+\mathrm{Z}-$ (4/9)YQ, so that:

$$
(\mathrm{a}-\mathrm{b})=(4 / 9) \mathrm{YQ} \text {. }
$$

Equation 22 can then be substituted into equation 9 to estimate the PR efficiency in different tissues.

The established use of equation 7 in the literature and the contraction of the effects of different tissues and proportions of active nuclei into a single power causes equation 22 to be very convenient for the purpose of comparing between different estimates as well as testing hypotheses. However, the exact equation 20 , instead of the approximate equation 21 , can be used to obtain the generally valid:

$$
\mathrm{PS} / \mathrm{PR}=\left[\mathrm{Q}\left\{(\mathrm{P} / \alpha)^{-(4 / 9) \mathrm{Y}}-1\right\}\right]^{-1}+1,
$$

for substitution in equation 2 .

Comparisons between the substitution of equation 23 in equation 2 , or of 22 in 9, show that the answers are often surprisingly close to each other. For example, in a concatenation of the most extreme values $\mathrm{P} / \alpha=0 \cdot 13, \mathrm{Q}=0 \cdot 31$ and $\mathrm{j}=(4 / 9)$ $\mathrm{Y}=2 / 27=0.074$ in Table 2 , the exact equation 23 gives $\mathrm{k}_{\mathrm{P}}=0.224$ and the approximate equation 22 gives $\mathrm{k}_{\mathrm{P}}=0.215$. This represents complete agreement in rounding to twofigure accuracy or an exact ratio of 0.962 . For $\mathrm{P} / \alpha=0.13$, 
Table 2. Estimates from equation 12 in the text, with conditional $\mathrm{Cl}$, of $\mathrm{j}$ (equation 25) according to tissue and method of estimation of protein synthesis by either a flooding dose (f) or constant infusion (i) in terms of either tissue intracellular- (ii) or plasma- (ip) specific activities

\begin{tabular}{|c|c|c|c|c|c|c|c|c|}
\hline Reference & Tissue & Method & Animal & $n$ & $\mathrm{P} / \alpha$ & $Q$ & j & Conditional $90 \% \mathrm{Cl}$ \\
\hline Sève et al. (1993) & Muscle & $f$ & Pig & 8 & 0.393 & 1.000 & 0.423 & $0.385-0.471$ \\
\hline Edmunds et al. (1980) & Muscle & ii & Pig & 12 & 0.130 & 0.583 & 0.422 & $0.330-0.589$ \\
\hline Preedy et al. (1983) & Muscle & $f$ & Rat & 6 & 0.225 & 0.563 & 0.417 & $0.385-0.457$ \\
\hline McNurlan \& Garlick (1980) & Digestive tract & $f$ & Rat & 30 & 0.167 & 0.563 & 0.075 & $0.068-0.082$ \\
\hline Edmunds et al. (1980) & Viscera & ip & Pig & 42 & 0.130 & 0.583 & 0.079 & $0.069-0.092$ \\
\hline Simon (1989) & Viscera & ip & Pig & 91 & 0.250 & 0.457 & 0.078 & $0.073-0.083$ \\
\hline Simon (1989) & Skin & ii & Pig & 3 & 0.250 & 0.457 & 0.237 & - \\
\hline Lobley et al. (1980) & Skin & ip & Cattle & 2 & 0.435 & 0.311 & 0.295 & - \\
\hline Davis et al. (1981) & Skin & ip & Sheep & 9 & 0.263 & 0.313 & 0.142 & - \\
\hline Lobley et al. (1980) & Bone & ip & Cattle & 1 & 0.444 & 0.307 & 0.223 & - \\
\hline Average & Skin & - & - & - & - & - & 0.222 & - \\
\hline Edmunds et al. (1980) & Liver & ip & Pig & 6 & 0.13 & 0.583 & 0.139 & $0.091-0.289$ \\
\hline Simon (1989) & Liver & ip & Pig & 11 & 0.25 & 0.457 & 0.166 & $0.138-0 \cdot 210$ \\
\hline Davis et al. (1981) & Liver & ip & Sheep & 9 & 0.263 & 0.313 & 0.121 & - \\
\hline Average & Liver & - & - & - & - & - & 0.146 & - \\
\hline
\end{tabular}

$n$, number of observations; $P / \alpha$, protein maturity; $Q$, estimate of the fraction of active nuclei.

$\mathrm{j}=(4 / 9) \mathrm{Y}=2 / 27$ and $\mathrm{Q}=\frac{1}{2}$, the approximate average lower value of $\mathrm{Q}$ for monogastrics in Table 2, the ratio between the answers from equations 23 and 22 is 0.976 . Note that, for $\mathrm{Q}$ or $\mathrm{P} / \alpha=1$, equations 20 and 21 , and hence 22 and 23 , are precisely equivalent, so that the nearer to $\mathrm{Q}$ or $\mathrm{P} / \alpha=1$, the better the approximations.

Depression v. stimulation. It is perhaps important to note that, instead of the stimulating transcription, the development could equally have been in terms of a depression of gene transcription. The relevant terminology would then be that of repressors binding to silencers, instead of activators binding to enhancers. The only difference in outcome would be a term (4/9)YQ added to a instead of subtracted from b, with $(a-b)$ remaining unaffected. Development in terms of stimulation of transcription is favoured as it seems to be of more general occurrence in gene control.

\section{Estimation of the proportion of active nuclei}

There is, at present, no way of directly estimating the proportion of active nuclei (Q) in vivo. Indirect estimates have, therefore, been devised by Roux (2005a) to comply with the basic property of a proportion, i.e. to vary between zero and 1. Hormonal concentration in the blood, taking for example IGF1 concentration, can be used to model Q in equation 22 by:

$$
\mathrm{Q}=\left\{\left[\mathrm{IGF}_{\mathrm{I}}\right]-\left[\mathrm{IGF}_{\mathrm{M}}\right]\right\} /\left\{\left[\mathrm{IGF}_{\mathrm{A}}\right]-\left[\mathrm{IGF}_{\mathrm{M}}\right]\right\},
$$

where $\left[\mathrm{IGF}_{\mathrm{I}}\right]$ denotes IGF concentration in the blood at an arbitrary level of energy intake, $\left[\mathrm{IGF}_{\mathrm{M}}\right]$ denotes concentration for intake at maintenance and $\left[\mathrm{IGF}_{\mathrm{A}}\right]$ denotes concentration for intake ad libitum. Since it is assumed that $\left(\mathrm{IGF}_{\mathrm{M}}\right] \leq$ $\left[\mathrm{IGF}_{\mathrm{I}}\right] \leq\left[\mathrm{IGF}_{\mathrm{A}}\right]$, it follows that $0 \leq \mathrm{Q} \leq 1$.

We can denote the general intake rate of metabolizable energy by $\mathrm{ME}_{\mathrm{I}}$, the rate of intake ad libitum by $\mathrm{ME}_{\mathrm{A}}$ and the maintenance intake rate by $\mathrm{ME}_{\mathrm{M}}$. Then, if intake rate and IGF concentration in the blood are linearly related (Roux, 2005a), the representation of $\mathrm{Q}$ in terms of IGF concentration is equivalent to a corresponding ratio in terms of intake rate:

$$
\mathrm{Q}=\left(\mathrm{ME}_{\mathrm{I}}-\mathrm{ME}_{\mathrm{M}}\right) /\left(\mathrm{ME}_{\mathrm{A}}-\mathrm{ME}_{\mathrm{M}}\right) .
$$

Roux (2005a) demonstrates that the application of equation 24.2 leads to predictions in agreement with experimental observations.

It follows from equations 24.2 and 22 that the intake ad libitum of an adequate diet $\mathrm{Q}=1$, so that at intake ad libitum $\mathrm{j}=$ $(a-b)=(4 / 9) Y$. Hence, with the value of $(a-b)$ with an intake ad libitum denoted by $\mathrm{j},(\mathrm{a}-\mathrm{b})$ at in the ad libitum condition can be estimated by:

$$
\mathrm{j}=(\mathrm{a}-\mathrm{b}) / \mathrm{Q}
$$

from equation 22 .

\section{Values of $Y$ and $j$}

The quantity $\mathrm{Y}$ is defined as the power in the relationship between $\mathrm{cv}$ and $\mathrm{P} / \alpha$, such that $(\mathrm{cv}) \propto(\mathrm{P} / \alpha)^{\mathrm{Y}}$. The number of multinucleate skeletal muscle cells does not increase after birth (Swatland, 1984) so that $\mathrm{Y}=1$ for skeletal muscle. Generally, the total amount of DNA, and hence nn, in the whole body of rats follows the relationship $(\mathrm{nn}) \propto(\mathrm{P} / \alpha)^{2 / 3}$ (Roux, 1999). Moss (1968) reports that this is also true for skeletal muscle as long as fibre length continues to increase. Hence $(\mathrm{nn}) \propto(\mathrm{P} / \alpha)^{2 / 3}$ must also be true for the mononucleate cells in the body. The derived relationship $(\mathrm{P} / \mathrm{nn}) \propto(\mathrm{P} / \alpha)^{1 / 3}$ implies that $\mathrm{cv}$ for the mononucleate cells scales as $(\mathrm{P} / \alpha)^{1 / 3}$ on average. Hence, by definition, $\mathrm{Y}=1 / 3$ on average for mononucleate cells. From equations 22 and 25, j=4/9 for muscle and $\mathrm{j}=4 / 27$ for total body mononucleate cells. A survey by Lobley et al. (1980), confirmed by Table 3, indicates that muscle PS accounts for about one quarter of total body PS. Hence, from equation 15, total body $\mathrm{j}=(1 / 4)(4 / 9)+(3 / 4)(4 / 27)=2 / 9$, in agreement with the value postulated and confirmed by Roux $(2005 a)$.

The mononucleate cells in the body can be divided into skin, bone and viscera. Enesco \& Leblond (1962) present evi- 
Table 3. The proportional contribution of different tissues to whole-body protein synthesis in rats (Preedy et al. 1983), pigs (Simon, 1989) and cattle (Lobley et al. 1980)

\begin{tabular}{lcccc}
\hline & Rats & Pigs & Cattle & Average \\
\hline Muscle & 0.25 & 0.30 & 0.20 & 0.25 \\
Viscera & 0.49 & 0.34 & 0.36 & 0.40 \\
Skin plus bone & 0.26 & 0.36 & 0.44 & 0.35 \\
\hline
\end{tabular}

dence of approximate values of $\mathrm{Y}=1 / 2$ for both skin and bone, and $Y=1 / 6$ for viscera. This produces $j=2 / 9$ for skin or bone, and $\mathrm{j}=2 / 27$ for viscera. We can assume equal contributions to PS from skin plus bone and viscera. Then, from equation 15, the contributions to total body $\mathrm{j}$ from muscle, skin plus bone and viscera are (1/4)(4/9) + $3 / 8(2 / 9)+(3 / 8)(2 / 27)=2 / 9$, again in agreement with Roux (2005a).

Analogous to the calculation of $\mathrm{j}$ from equation $15, \mathrm{Y}$ for the whole body can be calculated $\mathrm{Y}=(1 / 4)(1)+(3 / 4)$ $(1 / 3)=1 / 2$. Hence the proportional contributions, according to equation 15 , of the different tissues to the whole-body value of $\mathrm{j}$ can be summarized as follows:

$\begin{array}{cccccc}\text { Tissue } & \text { Proportion } & \text { Decimalvalue } & \mathrm{Y} & \mathrm{j} & \text { Decimalvalue } \\ \text { Muscle } & 1 / 4 & 0.25 & 1 & 4 / 9 & 0.444 \\ \text { Skinplusbone } & 3 / 8 & 0.375 & 1 / 2 & 2 / 9 & 0.222 \\ \text { Viscera } & 3 / 8 & 0.375 & 1 / 6 & 2 / 27 & 0.074 \\ \text { Mononucleatecells } & 3 / 4 & 0.75 & 1 / 3 & 4 / 27 & 0.148 \\ \text { Wholebody } & 1 & 1.0 & 1 / 2 & 2 / 9 & 0.222\end{array}$

In equation 26, the contributions of skin plus bone and viscera add to that of mononucleate cells, with the contributions of muscle and mononucleate cells adding to that of the whole body. The information in equation 26 summarizes the relationships that must be tested against experimental observations in order to evaluate the acceptability of the present theory. The practical consequences of equation 26 are illustrated in Table 1, where PR efficiencies that can be calculated from equations 2 or 9 are given. The values of body mass (W) are derived from the simplifying assumptions of a limit body mass of $200 \mathrm{~kg}$ and equal body protein proportions in all tissues during growth. Notable of the estimates in Table 1 are the remarkable differences between tissues and $\mathrm{P} / \alpha$ groups, all due to corresponding differences in protein turnover. Applying equation 26, the values for skin or bone are also applicable to the whole body.

\section{Experimental evidence}

\section{Nuclear:cytoplasmic ratio}

That nv increases continuously in conjunction with $\mathrm{cv}$ is shown by a histological study of the development of the human heart by Linzbach (1950). For the heart, this ontogenic relationship is $(\mathrm{nv}) \propto(\mathrm{cv})^{1 / 3}$, in contrast to the general biological rule that (nv) $\propto(\mathrm{cv})^{2 / 3}$ (von Bertalanffy, 1960), also subscribed to by Teissier (1941) on the basis of his calculations on the relationship between $n v$ and $c v$ in twenty-two cell types obtained from twenty-four mammalian species. In what follows, it will be shown that the general assumption of the $2 / 3$ power predicts correctly in all cases that could sustain a thorough examination, except the heart. For the heart, a parallel development of the equivalent of equation 22 on the basis of a $1 / 3$ power and $\mathrm{Y}=1$ gives $(\mathrm{a}-\mathrm{b})=(2 / 9) \mathrm{Q}$, in agreement with the whole-body and heart values given in Roux (2005a).

\section{Cell volume and tissue mass}

The parameter cv can be approximated by the tissue mass (tm) divided by the nn or amount of DNA in a tissue (Enesco \& Leblond, 1962). These authors measured the amount of DNA for the whole body, carcass, skin (including the hair), viscera (excluding the digestive tract) and digestive tract. The data were read from their graphs, and powers in the relationship $(\mathrm{cv}) \propto(\mathrm{tm})^{\text {power }}$ were calculated from loglinear regression between tm and DNA or number of nuclei. The results are as follows:

$\begin{array}{cccc}\text { Tissue } & \text { Power } & \text { SE } & \text { df } \\ \text { Total body } & 0.333 & 0.029 & 13 \\ \text { Carcass } & 0.361 & 0.030 & 15 \\ \text { Skin } & 0.509 & 0.036 & 22 \\ \text { Viscera } & 0.171 & 0.016 & 19 \\ \text { Digestive tract } & 0.095 & 0.013 & 24 \\ \text { Digestive tract } & 0.166 & - & - \\ \text { (protein adjusted) } & & & \\ \text { Liver } & 0.358 & 0.045 & 2 \\ \text { (nn adjusted) } & & & \end{array}$

From $4 \mathrm{~d}$ of age onwards, the relationship between total body protein and total empty body mass in rats is $\mathrm{P} \propto \mathrm{W}^{1.033}$ (SE (power) 0.0804, df 2), calculated from Winick and Noble (1965). Hence, it seems likely that $P \propto$ tm, approximately, for rats, and that this relationship will also generally be applicable to the body components. It follows that the same relationship can be assumed to hold between $\mathrm{cv}$ and protein mass as between $\mathrm{cv}$ and $\mathrm{tm}$.

Owing to water loss, the DNA-tm relationship changes from the prenatal to the postnatal period (Winick and Noble, 1965). A neonatal water loss is observable as a dip in graphs of the DNAtm relationship found in Enesco \& Leblond (1962), with the calculations of equation 27 made on data after the dip. The exception to this observation is the DNA-tm relationship of the digestive tract, suggesting that the water loss in this tissue occurs more gradually. The occurrence of water loss is indicated by prenatal and postnatal protein concentrations of about $0 \cdot 10$ and $0 \cdot 14 \mathrm{~g} / \mathrm{g}$, respectively, in the small plus large intestines of rats (Goldspink et al. 1984). The data of Goldspink et al. (1984) give tm $\propto \mathrm{P}^{0.922}$ (SE (power) 0.016, df 2). Combined with data from Enesco \& Leblond (1962) that DNA $\propto$ $\mathrm{tm}^{0.905}$ (SE (power) 0.013, df 24) from birth onwards, DNA $\propto$ $\left(\mathrm{P}^{0.922}\right)^{0.905}$ or DNA $\propto \mathrm{P}^{0.836}$. Hence, cv (protein adjusted) $\propto \mathrm{P} / \mathrm{DNA} \propto(\mathrm{P})^{0.166}$, as shown in equation 27.

Rat liver cells are diploid at birth, more and more of them becoming tetraploid as the animal ages. Consequently, Enesco \& Leblond (1962) had to calculate nn by taking the mean DNA 
content per nucleus into account. Using their data, the relationship of $\mathrm{cv}$ adjusted for $\mathrm{nn}$ was calculated as in equation 27 .

The power of 0.509 for the skin in equation 27 indicates that the increase in cell mass and cell number is of about equal importance in the increase in tm. No separate estimate is available for bone, but Enesco \& Leblond (1962) state that the carcass contained a proportion of 0.19 bone. If we assume a power of $1 / 3$ for muscle (Moss, 1968), then, analogous to the derivation of equation 21 from equation 20, the power for carcass would be expected to be $0 \cdot 19(1 / 2)+$ $0.81(1 / 3)=0.365$, in 0.99 proportional agreement with the directly calculated value 0.361 in equation 27 . Hence a value of $1 / 2$ for the power in the relationship between cv and $\mathrm{tm}$ or protein in bone can be assumed.

\section{Experimental evidence on $j$}

In this paper, $\mathrm{j}$ will be estimated from $(\mathrm{a}-\mathrm{b})=\ln (\mathrm{FPB} /$ $\mathrm{FPS}) / \ln (\mathrm{P} / \alpha)$, equivalent to equation 12 , and from $\mathrm{j}=$ $(\mathrm{a}-\mathrm{b}) / \mathrm{Q}$ (equation 25), FPB denoting fractional protein breakdown. Estimates for PS and fractional PS (FPS) rates are reasonably abundant in the literature, but often appear without estimates of fractional protein breakdown or retention (FPR) rates. If fractional body mass gains are available, and a power relationship between tm and body mass is assumed:

\section{fractional tissue retention rate}

$$
=\text { power (fractional body mass gain) }
$$

and:

$$
(\mathrm{P} / \alpha, \text { tissue })=(\mathrm{P} / \alpha, \text { body mass })^{\text {power }},
$$

as equation 28 is the defining differential equation of the power relationship in equation 29 .

For example, Sève et al. (1993) measured PS in the longissimus muscle of eight pigs receiving a high-protein diet by use of a flooding dose technique. The daily gain was $0.932 \mathrm{~kg}$, assumed to be applicable at synthesis measurement at $66.4 \mathrm{~kg}$. The power for the relationship between the longissimus mass and body mass is given as 1.07 by Sève et al. (1993), so that FPR (per d) in muscle can be estimated by $1.07(0.932 / 66.4)=$ 0.015 , according to equation 28 . The amount of protein in the whole body was obtained by assuming the experimentally measured protein content of the gain to be applicable to the whole body, $\mathrm{P}=12.82 \mathrm{~kg}$. The average protein $\alpha$ from Knap (2000) for all genotypes and sexes is 30.69 , so that, from equation $29,(\mathrm{P} / \alpha$ muscle $)=(12 \cdot 82 / 30 \cdot 69)^{1.07}=0.393$. On obtaining the fractional breakdown rate by subtraction from $\mathrm{FPS}=0.046$ (per d), equation 12 gives $(\mathrm{a}-\mathrm{b})=0.423$, equal to $\mathrm{j}$ in the first line of Table 2 . If correction by the power 1.07 is neglected, a value of $(\mathrm{a}-\mathrm{b})=0.417$ is obtained, showing that, if the true value of the power is unknown, reasonable approximations may be expected as the power corrections above and below the line tend to cancel in equation 12 . In the rest of this paper, a power equal to unity will be assumed.

The pigs used by Sève et al. (1993) received a diet apparently adequate in terms of maximal PR efficiency with an intake ad libitum, so that $\mathrm{Q}=1$, from equation 24.2. Hence, from equation 25 , the values of $(a-b)$ and $j$ are equal. It should, however, be borne in mind that even in the ad libitum condition, some diets might be so inadequate in nutritive value that $\mathrm{Q}=1$ is impossible (Roux, 2005a).

The correct way of estimating the SE of the variables $(a-b)$ and $\mathrm{j}$ is from the SD calculated from individual observations. Unfortunately, only mean FPS and their SE are generally available. One way out from this dilemma is to calculate the CI for FPS. These CI limits for FPS are then substituted in equations 12 and 25 to obtain limits of $\mathrm{CI}$ for $\mathrm{j}$. Since only the variation in FPS is taken into account, these are conditional CI, with the conditioning on all other variates in equations 12 and 25. As the experimental error in FPS is probably the most critical component of the experimental error in $\mathrm{j}$, it can be expected that the conditional $\mathrm{CI}$ will be a fair measure of the accuracy of estimates of j. The estimates for pig skeletal muscle from Sève et al. (1993) of $\mathrm{j}$ and its components, together with a $90 \%$ conditional $\mathrm{CI}$ for $\mathrm{j}$, are given in the first line of Table 2.

From the current point of view, the main problem with continuous-infusion techniques is that the tissue intracellular and plasma-specific activities lie reasonably far apart, with the true specific activity somewhere in between. Across species, however, blood leucine flux gives reasonably consistent estimates of synthesis rates, at about $30 \mathrm{~g} / \mathrm{kg}^{0.75}$ (Simon, 1989). Furthermore, both Lobley et al. (1980), with cattle, and Davis et al. (1981), with sheep, found that the plasma-specific activities of the tissues added approximately to that obtained from the leucine flux from blood. Hence, constant-infusion plasma-specific activities are preferred for estimating $(a-b)$ and $j$, unless definite reasons are found to prefer intracellular activities.

Using the data of Edmunds et al. (1980), plasma-specific activities provide FPS for both muscle and skin that are of such small magnitude as to predict either mass loss or zero gain. In these situations, therefore, intracellular specific activities are preferred. Knap (2000) reports that Large White pig females have a whole-body protein $\alpha=30.0 \mathrm{~kg}$, so that with $\mathrm{P}=3 \cdot 90, \mathrm{P} / \alpha=0 \cdot 130$. Edmunds et al. (1980) measured intakes: $\mathrm{ME}_{\mathrm{I}}=15 \cdot 01 / 25^{0.63}=1.976 \mathrm{MJ} / \mathrm{kg}^{063}$. From Agricultural Research Council (1981) values, $\mathrm{ME}_{\mathrm{M}}=0.719 \mathrm{MJ} /$ $\mathrm{kg}^{0.63}$ and $\mathrm{ME}_{\mathrm{A}}=4 \times \mathrm{ME}_{\mathrm{M}}$. Hence equation 24.2 gives $\mathrm{Q}=0.583$. The values of $\mathrm{j}$ in Table 2 then follow from a straightforward application of equations 12 and 25. For viscera, a combined plasma FPS $=0 \cdot 1580$ (per d) of the different components measured by Edmunds et al. (1980) were calculated, and measurement errors of the components are assumed to be independent in order to obtain a combined SE of 0.0125 . With FPR $=0.141$ (per d) and P/ $\alpha=0.130,(a-b)=0.0458$ (equation 12), so that $\mathrm{j}=0.0458 / 0.583=0.079$ (Table 2).

Problems of measuring or estimating one or more of the components of equation 24.2 necessitate a different approach in all other cases, except for the studies by Sève et al. (1993) and Edmunds et al. (1980). The alternative approach is to estimate $\mathrm{Q}$ conditional on $\mathrm{j}$ for the total body equal to $2 / 9$ (Roux, 2005a) or to $4 / 9$ for muscle and to calculate $\mathrm{Q}=(\mathrm{a}-\mathrm{b}) / \mathrm{j}$ from equation 25 .

For example, Davis et al. (1981) estimate blood leucine FPS $=0.0777$ (per d), and total body FPR $=0.0069$ (per d) follows from an assumption that the PR of the unmeasured control is equal to that of the measured one. If we assume $\mathrm{P} / \alpha=0.263, \quad$ then $\quad(\mathrm{a}-\mathrm{b})=0.0696, \quad \mathrm{Q}=0.0696 /$ $0 \cdot 2222=0 \cdot 313$, from equation 25. For muscle (Davis et al. 1981) intracellular FPS $=0.0433$ (per d) as the average of two muscles, so that $(\mathrm{a}-\mathrm{b})=0.130$ (equation 12), and 
$\mathrm{j}=0 \cdot 130 / 0 \cdot 313=0 \cdot 415$, as given in Table 2 . Note that, with this approach, the precise value of $\mathrm{P} / \alpha$ is not important as it cancels in the ratio when calculating $\mathrm{j}$.

In the situation of Preedy et al. (1983), a value of Q was obtained from the related experiment of McNurlan \& Garlick (1980). According to Southon et al. (1985), daily gain in body mass for rats fed ad libitum a diet of commercial pellets in the range $100-300 \mathrm{~g}$ is $6.75 \mathrm{~g} / \mathrm{d}$. McNurlan \& Garlick's (1980) rats had a mass of $100 \mathrm{~g}$, hence $\mathrm{FPR}=0.0675$ (per d), assuming a constant body protein content for rats (see the discussion on equation 27). Using this assumption, the $100 \mathrm{~g}$ body mass and limit body mass of $600 \mathrm{~g}$ for rats given by Goldspink and Kelly (1984) suggest $\mathrm{P} / \alpha=$ 0.1667. McNurlan \& Garlick (1980) estimated a whole body $\mathrm{FPS}=0.336$ (per d). Hence, equation 12 gives $(\mathrm{a}-\mathrm{b})=0 \cdot 125$, so that $\mathrm{Q}=0 \cdot 125 / 0 \cdot 222=0 \cdot 563$. For the digestive tract, it is possible to calculate $\mathrm{FPS}=0.9319$ (per d). Hence $(a-b)=0.042$ from equation 12, and $\mathrm{j}=0 \cdot 042 / 0 \cdot 563=0.075$, as given in Table 2. The $135 \mathrm{~g}$ rats described by Preedy et al. (1983) had an FPR $=0.05$ (per d) and $\mathrm{P} / \alpha=0.225$ on the same basis as for the rats of McNurlan \& Garlick (1980). Preedy et al. estimated FPS $=0.169$ for muscle, so that $(a-b)=0.235$ (equation 12), $\mathrm{j}=0 \cdot 235 / 0.563=0.417$, as in Table 2 .

Since Simon (1989) obtained his whole body FPS by summation over tissues, including the viscera, it seems better to estimate $Q$ from muscle on the basis of $j=4 / 9$. This is justified as Table 2 provides enough evidence that $\mathrm{j}$ for muscle does not deviate significantly from the expected 4/9 (equation 26). Since the values for intracellular FPS in muscle in Table 9.18 of Simon (1989) do not differ significantly, their weighted average was obtained with weights equal to the inverse of their variances; FPS $=0.0489$ (per d). From Table 9.16 of Simon (1989), FPR $=0.6 / 50=0.012$ (per d), $\mathrm{P} / \alpha=50 / 200=0.25$, as the pigs grew at $0.6 \mathrm{~kg} / \mathrm{d}$ and had a mean body mass of $50 \mathrm{~kg}$ and an assumed limit mass of $200 \mathrm{~kg}$. This gives $(\mathrm{a}-\mathrm{b})=0.203$ (equation 12), so that $\mathrm{Q}=0 \cdot 203 / 0 \cdot 444=0 \cdot 457$. Since the body composition for the pigs in Table 9.18 of Simon (1989) is unavailable for calculating weights, the simple arithmetic average of the nine visceral traits in the table is taken as representative of the viscera as a whole; FPS $=0.250$ (per d). Hence $(a-b)=0.0355$ and $\mathrm{j}=0.0355 / 0 \cdot 457=0.078$, as in Table 2 .

The values of $\mathrm{j}$ for skin in Table 2 were calculated in the same way as for muscle and viscera. SE are not available for calculating CI. The value for bone was obtained by subtracting muscle from carcass values taken from Lobley et al. (1980). The value for bone of only one of two animals, with a realistic value of $\mathrm{j}$ near to $4 / 9$ for muscle, is reported. The other animal had a value of $\mathrm{j}=0.72$, indicating bias in the muscle estimate, and consequently too small an estimate of $\mathrm{j}$ for bone.

The estimates of Preedy et al. (1983) for skin and bone do not fit into the present context as the FPS are expressed in terms the protein fraction soluble in dilute alkali. In a growth context, it is synthesis and breakdown in relation to the total protein content of the tissues that are important and in terms of which the theory of equations 4-9 is developed. There is no problem with estimates of the relative contributions of skin and bone to whole-body PS from Preedy et al. (1983), which is, of course, the reason why their experiment was carried out.
The outcome of the evidence presented so far in Table 2 is that the estimates of $\mathrm{j}$ are in close agreement with the predictions made in equation 26. In addition, in all cases in which CI could be calculated, the predictions in equation 26 are encompassed by them.

From the discussion on equation 27, it seems likely that the liver would be representative of the behaviour of mononucleate cells in the body as $(\mathrm{cv}) \propto(\mathrm{tm})^{0.36}$, calculated from Enesco \& Leblond (1962), is not significantly different from $(\mathrm{cv}) \propto(\mathrm{tm})^{1 / 3}$. The evidence in Table 2 compared with equation 26 indicates that this is indeed the situation. The calculations of the plasma values for the constant-infusion technique in Table 2 are analogous to those for muscle or viscera, so no further comment is necessary. With floodingdose measurements on the liver, an adjustment is necessary to obtain a value comparable to the others.

As the liver synthesizes a considerable amount of protein for export, detected by flooding but passed over by constant-infusion estimates (Simon, 1989), some form of correction is necessary to make the values comparable. Conceptually, this can be done in two ways. The first is to combine the export and import tissues into a single unit and estimate $\mathrm{j}$ for such a combination. However, the requisite data are unavailable to do this. The second option is to partition the FPS in some way between protein export and retention. In 4-d-old rats, Conde \& Scornick (1977) estimated that a fraction of 0.39 of PS is retained, compared with an adult value of 0.48 . Taking the average, this gives FPS $=0.435 \times 1.054=0.458$ (per d) from McNurlan $\&$ Garlick (1980). In conjunction with the rest of the estimates provided for the digestive tract, $(\mathrm{a}-\mathrm{b})=0.089$ (equation 12), $\mathrm{j}=0 \cdot 089 / 0 \cdot 563=0 \cdot 158$, given in Table 2 . The predicted value of 0.148 falls within the associated conditional CI in Table 2. The average of all the liver values in Table 2 of 0.146 is also very near to the predicted value for mononucleate cells in equation 26. The conclusion follows that the liver can be regarded as a tissue representative of the mononucleate cells in the body. However, the width of the CI in Table 2 indicates that a reasonably large number of observations are necessary for accuracy of estimation.

\section{Proportional contributions to whole-body protein synthesis}

In the theoretical derivation of equation 26, proportional contributions to whole-body PS rates are conjectured or accepted that would add to a whole body $\mathrm{j}=2 / 9$, postulated and confirmed by Roux (2005a). Experimental estimates in agreement with the theoretical postulates of $\mathrm{j}$ (equation 26) are presented in Table 2. This agreement raises the question of whether there is experimental evidence to confirm the proposed proportions in equation 26.

Table 3 of the proportional contributions of different tissues to whole-body PS was constructed analogous to Table 9.21 of Simon (1989), under the following assumptions/procedures:

1. For rats, the figures are derived from a similar table by Preedy et al. (1983). The 'viscera' category was used to force the contributions to add to the whole body estimate derived from McNurlan \& Garlick (1980).

2. For pigs, the data were derived from previously unpublished work from Simon's (1989) laboratory. Since they do not differ much, the average of the plasma and intracellular estimates of relative contributions are taken, and 
the 'other' category is regarded as mainly the contribution from bone.

3. For cattle, the heifer plasma estimates from Lobley et al. (1980) were taken as their contribution approximately added to the blood leucine estimate, with reasonable interspecies agreement (Simon, 1989). The bone contribution is the difference between those of carcass and muscle.

The small number of species involved makes it difficult to judge whether the size trend from rats to cattle in the ratio (viscera)/(skin plus bone) between the proportions in Table 3 is significant. The average proportions of the three species are, however, in reasonable agreement with the triadic postulate of equation 26 , with perfect agreement on the binary postulate of muscle $v$. mononucleate cells.

\section{Comparison with an alternative approach}

The mathematical form of the current approach is mainly dictated by the cellular and hormonal mechanisms involved in the control of protein growth. In the description of protein growth, the ensuing theory is comparable to an approach derived from growth postulates of Baldwin \& Black (1979). This can be demonstrated by the transformation of PS rate as a DNA power relationship to a protein content power relationship by substituting DNA $\propto(\mathrm{P} / \alpha)^{2 / 3}($ Roux, 1999). For the wholebody situation, it follows that the relationships of Oltjen et al. (1985) provide an estimate of PR efficiency on rats from weaning onwards identical to the present one derived from equations 9 and 22 , with $\mathrm{Q}=1$ and $\mathrm{Y}=1 / 2$ (Roux, 2005a). In the twoprotein-pool situation of DiMarco et al. (1989), the comparison is complicated by the use of a function to describe PS that is more complex than that of the single-pool situation. One way round this obstacle is to fit power curves to the simulated rates published by DiMarco et al. (1989).

DiMarco et al. (1989) considered two protein pools: body and viscera. Body consisted mainly of skin, muscle and bone; viscera included blood, liver, digestive tract, heart and lungs. In evaluating the function of these, DiMarco et al. (1989) obtained initial values from Lobley et al. (1980). The parameters were then further modified to fit the protein growth of a reference steer, as described by growth and body composition equations. DiMarco et al. (1989) assumed that the body and viscera made equal contributions to whole-body synthesis rates, indicating that they judged contributions by estimates of synthesis rates from the tissue intracellular-specific activities of Lobley et al. (1980). Furthermore, this indicates an approximate one third contribution from muscle and a two-thirds contribution from skin and bone to body synthesis rates. From a similar derivation of equation 26, a predicted $\mathrm{j}$ (equation 25) for body is as follows:

$$
\mathrm{j}=(1 / 3)(4 / 9)+(2 / 3)(2 / 9)=8 / 27=0 \cdot 296 .
$$

DiMarco et al. (1989) predicted protein synthesis and degradation rates according to empty body mass, with four approximately $100 \mathrm{~kg}$ intervals of 131 to $520 \mathrm{~kg}$. By using initial values from DiMarco et al. (1989), together with composition values calculated for the reference steer, fits of equations 4 and 5 to their Table 1 give estimates of $(a-b)=0.324$ for body and $(\mathrm{a}-\mathrm{b})=0.078$ for viscera. The value for body is near to that of equation 30 and for viscera near to that of equation 26. The conclusion follows that values derived from DiMarco et al. (1989) are in reasonably close agreement with those following from equations 22 and 25 , with $Q=1$. As simulated data cannot be regarded as sequentially independent, significance tests are not possible.

\section{Discussion}

Predictions of powers involved in protein efficiency estimates in the equation 26 and the experimental estimates in Table 2 show highly satisfactory agreement. This bolsters confidence in the soundness of the arguments employed in deriving the key equations 16-20. The basic assumption in deriving the pivotal equation 18 is that, for growth purposes, gene transcription and consequent PS are proportional to the concentration of growth factor-derived activator in the nucleus. A direct measurement of these basic molecular quantities would put the postulated causal mechanisms beyond dispute. From the review by Levine and Tjian (2003), it is clear that, in the development of protocols for such a molecular approach, virtually the whole field of gene transcription regulation will have to be taken into account. The advantages of size and availability suggest, as a starting point, concentration on the most abundant muscle protein, myosin, for which much information on myosin heavy chain genes is available (Goldspink, 1991). The previous measurement of nuclear size from heart muscle (Linzbach, 1950) suggests the possibility of a similar approach for skeletal muscle, so that direct confirmation of such a relationship between myosin synthesis and nuclear size, as postulated in the derivation of equations 17 and 18 , should be able to be accomplished.

The most immediate possibility for applying the present approach to estimating PR efficiency lies in the estimation of nutrient requirements for growth. Here, the relevant equation would be $\mathrm{ME}=$ Maintenance $+\Sigma \mathrm{PR}_{\mathrm{i}} / \mathrm{k}_{\mathrm{Pi}}+\mathrm{FR} / \mathrm{k}_{\mathrm{F}}$, with $\mathrm{PR}_{\mathrm{i}}$ denoting $\mathrm{PR}$ and $\mathrm{k}_{\mathrm{Pi}}$ efficiency for the ith component (muscle, skin plus bone or viscera), FR fat retention and $\mathrm{k}_{\mathrm{F}}$ fat retention efficiency. For whole-body protein, the factors involved in such an approach to nutrient requirements have been given by Roux (2005a) for pigs and Roux (2005b) for cattle and sheep. The subdivision of whole-body protein does not seem to add any new complexities, while it is possible to allow for differences in the tissue composition of whole-body protein for stock of different breeds or lines. The general approach could be similar to that followed for maintenance in pigs by van Milgen et al. (1998). Furthermore, if preference should be given to an alternative accommodation of turnover instead of retention efficiency in maintenance (Roux, 2005a), turnoverrelated PR efficiencies could also be employed for the estimation of the turnover costs contributed by different types of tissues.

Estimation of the proportion $(\mathrm{Q})$ of active nuclei in a tissue plays an indispensable part in predicting protein efficiency from equations 9 and 22, or 2 and 23. There is, at present, no way of directly estimating Q. The most practical way to obtain estimates is to use intake rates, as proposed in equation 24.2. In pigs, all eight estimates of $Q$ obtained from intake rates (equation 24.2) in Roux (2005a) gave predictions consonant with $\mathrm{j}=2 / 9$ from equation 25 , with $\mathrm{Y}=1 / 2$ for wholebody protein, in line with theoretical expectation. In cattle, an example was found that motivated a general rule for calculations with suboptimal diets. The rule is to take $\mathrm{ME}_{\mathrm{A}}$ in equation 24.2 as the conceptual intake associated with 
whole-body $(\mathrm{a}-\mathrm{b})=2 / 9$ and $\mathrm{ME}_{\mathrm{I}}$ as the actual intake of the diet under consideration. The application of this rule is illustrated in Roux (2005b) and justified by comparison with an independent estimate of $(a-b)$ obtained from multiple regression. In sheep, evidence derived from estimates of conventional multiple regression efficiencies suggests that the rule $(a-b)=(2 / 9) Q$ for the calculation of $k_{P}$ should be reserved to describe compensatory growth. PR efficiency for ordinary growth should be described by an adaptation of the rule derived for suboptimal intake (Roux, 2005b).

It follows from equation 24.1 that suboptimal performance may possibly be elucidated from hormonal causes. From Roux (2005a), a necessary caveat in this context is that it may be misleading to consider IGF concentration in isolation, as other hormones, for example glucocorticoids, may inhibit gene transcription directly.

Measurement or estimation problems associated with intake or maintenance allowed an estimation of Q from equation 24.2 in Table 2 only for the estimates from Sève et al. (1993) and Edmunds et al. (1980). For the other cases, estimates of Q were conditional on $\mathrm{j}$ for the total body equal to 2/9 (Roux $2005 a$ ), or conditional on $\mathrm{j}$ for muscle equal to $4 / 9$, calculating $\mathrm{Q}$ from equation 25 , with $\mathrm{Y}=1 / 2$ or $\mathrm{Y}=1$ respectively. This probably caused the avoidance of complications in the estimation of Q owing to suboptimal intake or performance that was reported in Roux (2005b). The consistent estimates of $\mathrm{j}$ within tissues in Table 2 suggest that the proportions of active nuclei $(\mathrm{Q})$ between tissues are the same under restricted intakes. This conclusion is in agreement with the results calculated from intake Q for Edmunds et al. (1980) in Table 2, all three groups of tissue behaving according to expectation in equation 26 .

To allow illuminating comparisons between the whole body and its components, and for flexibility in testing hypotheses, approximations of arithmetic means by types of geometric mean have been made in equations 15 and 21. Although advantageous for current purposes, the following example shows that this may not always be the case. The use of the approximate equation 21 instead of 20 can lead to serious bias, for $\mathrm{Q} \neq 1$, in the application of von Bertalanffy's (1960) formula $(\mathrm{P} / \alpha=$ $\left.(\mathrm{b} / \mathrm{a})^{1 /(a-b)}\right)$ for the growth inflection point, since both the ratio and the difference between $\mathrm{a}$ and $\mathrm{b}$ are involved.

\section{References}

Agricultural Research Council (1981) The Nutrient Requirements of Pigs. Slough: Commonwealth Agricultural Bureaux.

Baldwin RL \& Black JL (1979) Simulation of the Effects of Nutritional and Physiological Status on the Growth of Mammalian Tissues. Animal Res. Lab. Tech. Paper No.6. Clayton South, Victoria, Australia: Commonwealth Scientific and Industrial Research Organization.

Bergen WG \& Merkel RA (1991) Protein accretion. In Growth Regulation in Farm Animals, pp. 169-198 [AM Pearson and TR Dutson, editors]. London: Elsevier Applied Science.

Blaxter KL (1989) Energy Metabolism in Animals and Man. Cambridge: Cambridge University Press.

Conde RD \& Scornick OA (1977) Faster synthesis and slower degradation of liver protein during developmental growth. Biochem $J$ 166, 115-121.

Czech M (1989) Signal transmission by the insulin-like growth factors. Cell 59, 235-238.

Davis SR, Barry TN \& Hughson GA (1981) Protein synthesis in tissues of growing lambs. Br J Nutr 46, 409-419.
DiMarco ON, Baldwin RL \& Calvert CC (1989) Simulation of DNA, protein and fat accretion in growing steers. Agric Syst 29, 21-34.

Edmunds BK, Buttery PJ \& Fisher C (1980) Protein and energy metabolism in the growing pig. In Energy Metabolism, pp. 124-133 [LE Mount, editor]. London: Butterworths.

Enesco M \& Leblond CP (1962) Increase in cell number as a factor in the growth of the organs and tissues of the young male rat. $J$ Embryol Exp Morph 10, 530-562.

Goldspink G (1991) Prospectives for the manipulation of muscle growth. In Growth Regulation in Farm Animals, pp. 557-588 [AM Pearson and TR Dutson, editors]. London: Elsevier Applied Science.

Goldspink DF \& Kelly FJ (1984) Protein turn-over and growth in the whole body, liver and kidney of the rat from the foetus to senility. Biochem J 217, 507-516.

Goldspink DF, Lewis SEM \& Kelly FJ (1984) Protein synthesis during the developmental growth of the small and large intestine of the rat. Biochem $J$ 217, 527-534.

Knap PW (2000) Time trends of Compertz growth parameters in meat-type pigs. Anim Sci 70, 39-49.

Latchman DS (2005) Gene Regulation, 5th ed. Abingdon: Taylor \& Francis.

Levine M \& Tjian R (2003) Transcription regulation and animal diversity. Nature 424, 147-151.

Linzbach AJ (1950) The muscle fibre constant and the law of growth of ventricles of the human heart. Virchows Arch 318, 575-618.

Lobley GE, Milne V, Lovie JM, Reeds PJ \& Pennie K (1980) Whole body and tissue protein synthesis in cattle. Br J Nutr 43, 491-502.

McNurlan MA \& Garlick PJ (1980) Contribution of rat liver and gastrointestinal tract to whole body protein synthesis in the rat. Biochem J 178, 373-379.

Moss FP (1968) The relationship between the dimensions of the fibres and the number of nuclei during normal growth of the skeletal muscle in the domestic fowl. Am J Anat 122, 555-564.

Oltjen JW, Bywater AL \& Baldwin RL (1985) Simulation of normal protein accretion in rats. $J$ Nutr 115, 45-52.

Preedy VR, McNurlan MA \& Garlick PJ (1983) Protein synthesis in skin and bone of the young rat. Br J Nutr 49, 517-523.

Roux CZ (1999) Growth equations for skeletal muscle derived from the cytonuclear ratio and growth constraining supplementary functions. Anim Sci 68, 129-140.

Roux CZ (2005a) Incorporating turn-over in whole body protein retention efficiency in pigs. Anim Sci 80, 71-81.

Roux CZ (2005b) Incorporating turn-over in whole body protein retention efficiency in cattle and sheep. Anim Sci 80, 345-351.

Sève B, Ballèvre O, Ganier P, Noblet J, Prugnaud J \& Obled C (1993) Recombinant porcine somatotropin and dietary protein enhance protein synthesis in growing pigs. $J$ Nutr 123, 529-540.

Simon O (1989) Metabolism of proteins and amino acids. In Protein Metabolism in Farm Animals, pp. 367-403. [HD Bock, BO Eggum, AG Low and T Zebrowska, editors]. Oxford: Oxford University Press.

Southon S, Livesey G, Gee JM \& Johnson IT (1985) Differences in intestinal protein synthesis and cellular proliferation in well-nourished rats consuming conventional laboratory diets. Br J Nutr 53, 87-95.

Swatland HJ (1984) Structure and Development of Meat Animals. Englewood Cliffs, NJ: Prentice Hall.

Teissier G (1941) Sur le rapport nucléoplasmatique des cellules de mammifères. Compt rend soc boil 135, 662-666.

van Milgen J, Bernier JF, Lecozler Y, Dubois S \& Noblet J (1998) Major determinants of fasting heat production and energetic cost of activity in growing pigs of different body weight and breed/ castration combination. Br J Nutr 79, 509-517.

von Bertalanffy L (1960) Principles and theory of growth. In Fundamental Aspects of Normal and Malignant Growth, pp. 137-259 [WW Nowinski, editor]. Amsterdam: Elsevier.

Winick M \& Noble A (1965) Quantitative changes in DNA, RNA and protein during prenatal and postnatal growth in the rat. Dev Biol 12, 451-466. 